\title{
THE ANALYSIS OF DERIVATION IN CONVERSATION SCRIPTS
}

\author{
Atikah Wati \\ S1 - English Education Department \\ Wiralodra University - Indramayu \\ atikah_wati@unwir.ac.id
}

\begin{abstract}
Word derivation make the conversation more simple and specific to the topic. The case is many students didn't recognise and aware of using it. this paper is trying to reveal the words derivation that the students use in their speaking class conversation whether or not it affected to the semantic. Dealing with vocabulary and grammar, speakers often choose certain vocabulary to express something and forming it into the correct grammatical rules, the choice of vocabulary that the speaker use during the planned speaking activity in the classroom and how this words implemented with the correct grammar in the form of literature dealing with morphology and semantic are the main focus of this paper. Many students didn't really aware with the use of derivational words, 3 numbers of students conversational scripts didn't insert any derivational words at all. While the other 2 insert very little derivational words. The method of analysis that the writer use to reveal the processes of derivation in more detail by noting three simultaneous processes, namely: a morphological process (e.g. changing the shape of an existing word by adding a prefix or suffix morpheme to an existing root morpheme) a syntactic process (changing the part of speech of a word, e.g. from verb to noun) and a semantic process (producing a new sense, agent, act, property).
\end{abstract}

Keywords : speaking, conversation script, derivation, morphology and semantic

\section{INTRODUCTION}

Speaking as one of productive skill along with writing needs to be specific in the hope that the interlocutors understand completely what the speaker intended to say. Speaking is a skill, but it doesn't mean that all speakers are skillful which can be assumes of having some kind of knowledge base. To play piano well requires some kind of musical knowledge. Of course, the knowledge base for speaking in the first language is largely intuitive; it is not something a person is normally sufficiently aware of to be able to describe. For the second or foreign language learners, the knowledge base of sociocultural knowledge, genre, speech acts, 
register, discourse, grammar, vocabulary and phonology are needed to be able to convey something correctly along with intuitive (Thornburry, 11).

Dealing with vocabulary and grammar, speakers often choose certain vocabulary to express something and forming it into the correct grammatical rules. The writer of this paper try to seek the choice of vocabulary that the speaker use during the planned speaking activity in the classroom and how this words implemented with the correct grammar in the form of literature dealing with morphology and semantic.

In University where I teach, speaking class which conducted in 4 semester divided into speaking $1,2,3$, and 4 , required the students to be able to be skillful in many purposes of speaking. One of it is the interpersonal purpose which its primary purpose is to establish and maintain social relations (Thornburry :13). Sepaking 1 and 2 are focus on this interpersonal purpose, it can be seen from the activity in the speaking 1 and 2 class. The lecturer of speaking 1 and 2 required the students to create a conversation related to the simple social topic like time for change, mariage costums, etc. The topic coosen by the lecturer, the students are suppose to create planned conversation in pair of course regarding to the topic, after that the students have to perform it in front of the class. So, each student have the script of conversation related to the topic.

Word derivation make the conversation more simple and specific to the topic. The case is many students didn't recognise and aware of using it. this paper is trying to reveal the words derivation that the students use in their speaking class conversation whether or not it affected to the semantic.

In the literature dealing with derivational morphology, one of the most intricate issues is the question of how the semantic influence of the derivational affix on its derivative may best be represented in the respective modelling of derivational processes. In recent work on derivational morphology, it is frequently assumed that the systematic polysemy and the functional diversity of the affixes is best represented in a multi-layered model in which the influence of the affixes on the semantic contribution of the base may be modelled at a highly abstract layer of morphological representation (Workshop at the University of Stuttgart, May 3031 2008). This paper analysis will be focus on how words derivational process influence the semantic meaning in conversation scripts in the hope that by understanding and the awareness of the use of derivation words, the students' speaking skill will improve significantly.

\section{Factual problem}

The derivational processes can change the pattern of the words e.g. $\mathrm{N}$ become $\mathrm{V}$, etc. it also can make the meaning of certain word broader as well as more specific. Using the derivation words, the speakers don't have to explain something in very long explanation. The problem is, many speakers didn't really aware or recognise the implementation of derivation in their speech. Some even didn't really know the meaning of derivation words in their conversation. Base on that, this paper is trying to reveal and analyse the use of derivation in students conversation script. So the statement of problem can be concluded:

"How is the words derivation influence the semantic meaning in students conversation scrips?" 


\section{THEORETICAL REVIEW \\ Speaking in general}

As the writer focuses only on speaking skill, the writer will not discuss the written one. Speaking is a part of daily life. The average person produces tens of thousands of words a day. Speaking is natural and integral that we forget how we once struggled to achieve this ability, and now we have to learn how to do it all over again in a foreign language. David Nunan (1999:225) says: "the ability to function in another language is generally characterized in terms of being able to speak that language." Speaking is such a fundamental human behavior that we don't stop to analyze it unless there is something noticeable about it,. Speaking consists of producing systematic verbal utterances to convey meaning.

There are two main purposes for speaking. Speaking serves either as a transactional function, in that its primary purpose is to convey information and facilitate the exchange of goods or services, or as an interpersonal function, in that its primary purpose is to establish and maintain social relationship.

\section{CONVERSATION}

Conversation definition from Miriam Webster, conversation is an oral exchange of sentiments, observations, opinions, or ideas; an instance of such exchange: an informal discussion of an issue by representatives of governments, institutions, or groups.

Examples of conversation:

Do you remember our conversation about that new movie?

We got into a long conversation about his behavior.

They were engaged in a lengthy conversation about politics.

The topic came up in conversation.

They were so deep in conversation that they barely noticed me.

He kept trying to engage me in conversation.

She's skilled in the art of conversation

\section{Script}

From free dictionary, script is handwriting as distinguished from print, esp cursive writing; the letters, characters, or figures used in writing by hand; any system or style of writing; (Performing Arts) written copy for the use of performers in films and plays; an original or principal document; (esp in England) a will or codicil or the draft for one; (Communication Arts / Printing, Lithography \& Bookbinding) any of various typefaces that imitate handwriting; (Social Science / Education) an answer paper in an examination.

Based on the definition of conversation and script above, we can conclude that the conversation script that the writer use in this paper is the script that the students use for their conversation in the from of dialogue.

\section{DERIVATION}

Derivation forms a word with a meaning and/or category distinct from that of its base through the addition of affix. (O'grady, 1997: 144). Derivation is the process of forming new words according to a regular pattern on the basis of pre-existing word. 
New words may be formed by combining existing words with meaningful units smaller than words, or with other existing words, according to derivational patterns or rules that are part of every speaker's mental knowledge of the language. There is a special technical term used by linguists to describe the basic components that make up derived words.

A morpheme is a minimal unit of word building that combines a minimal unit of meaning with a minimal linguistic form that carries this meaning. (The word morphological is an adjective derived from this term.)

Morphemes are the building blocks of word derivation in language. Note that, according to this definition, the class of morphemes in a language is not restricted to just the class of free-standing words. The definition has to be general enough to include units smaller than actual words, such as prefixes and suffixes that also combine minimal forms with minimal units of meaning and can be used to construct new words.

An existing word such as $d o g$ is a morpheme because it combines a minimal unit of meaning (i.e. whatever it is we understand the word $d o g$ to mean) with a minimal linguistic form, consisting of three speech sounds represented here by the letters used to spell the word. The form is minimal because it is not possible to convey the meaning of $d o g$ by any smaller set of sounds than the three sounds that make up the word as we know it. For example, we can't suddenly start referring to a dog as an *og (by leaving off the initial consonant sound represented by the letter $d$ ) or as a *do (by leaving off the final consonant sound represented by the letter $g$ ). Similarly, the meaning is minimal because it is also not possible to somehow divide the meaning of the word form $d o g$ into smaller parts which would have anything to do with dogs as we know them.

A unit smaller than an actual word, such as the suffix -er in the word builder, is also a morpheme, because it combines a minimal meaning (something like 'an entity that engages in the activity described by the verb that it attaches to') with a minimal linguistic form, consisting of the two speech sounds represented by the letters used to spell the suffix. Another unit smaller than an actual word, such as the prefix $r e$ - in the word replay, is also a morpheme, because it combines a minimal meaning (something like 'repeat the activity described by the verb that it attaches to') with a minimal linguistic form, consisting of the two speech sounds represented by the letters used to spell the prefix. It can be say that the derived word builder is formed by attaching the suffix -er after the root word build and the derived word replay is formed by attaching the prefix re-before the root word play. The root words in each case clearly convey the core, fundamental meanings of the derived words. Prefixes always attach before the root morpheme and suffixes attach after the root morpheme.

\section{Different types of derivation}

There are four different types of derivational relationship between words: addition, mutation, conversion and subtraction.

Addition: Some lexemes are formed by combining morphemes: those like armchair and busybody, which consist entirely of free morphemes; words like violinist, disarm and blue-eyed, which have partly free and partly bound morphemes; and the type represented by astronaut and biology, composed entirely of bound morphemes. 
Mutation: The words proud and pride are semantically related and are related formally as well, but it is impossible to say that one is formed by adding something to the other. Rather, derivation is accomplished here by a change of vowel; in other pairs of words the change may be in consonants, as in believe and belief; or both vowel and consonant, as with choose and choice; or by change of stress: e.g. verbs extráct, insúlt, progréss in contrast to nouns extract, insult, progress.

Conversion or Zero change: This is the simple change of a word of one class to a word of another class with no formal alteration. Thus clean, dry and equal are adjectives and also verbs; the relation of the adjective clean to the verb clean is the same as that of the adjective long to the verb lengthen. Fan, grasp and hammer are verbs and also nouns; capital, initial and periodical are nouns and adjectives.

Subtraction (or reduction): By removing parts of certain lexemes new lexemes are formed. One kind of shortening is called an acronym; another is called a clipping. An acronym is a word derived from the written form of a construction; a construction is a sequence of words that together have a meaning. Some acronyms are pronounced as a sequence of letters: $U K$ for 'United Kingdom,' USA for 'United States of America.' In other acronyms the letters combine to produce something pronounceable: AIDS for 'Acquired Immune Deficiency Syndrome,' UNESCO for 'United Nations Educational, Scientific, and Cultural Organization.' As these examples show, the acronym is typically but not always formed from the first letter of each written word. The acronym may be formed from parts of a single word: ID for identification, $T B$ for tuberculosis, $T V$ for television; or it may include more than initial letters: Nabisco (National Biscuit Company), Sunoco (Sun Oil Company). With a few exceptions, acronyms are essentially names (Kreidler 1979).

Another process applied to existing words is clipping, the use of part of a word to stand for the whole word. Laboratory is abbreviated to lab, telephone to phone, refrigerator to fridge. Sometimes a vowel is added when other material is cut away, as in Chevy for Chevrolet, divvy for dividend, ammo for ammunition. In these examples and many others we see only new, shorter ways of designating what was previously designated by a longer term, but sometimes clipped forms come to have meanings that are distinct from the original sources. The part of speech may change (a kind of conversion): divvy, just cited, is used as a verb whereas dividend is a noun. Without a change in part of speech the clipped form may have a connotation different from the source word: hankie, undies, nightie are 'cuter' than handkerchief, underwear, nightgown, respectively.

\section{Previous studies Versus this study}

Most of study of semantic derivation is in the form of TAG (tree adjoining grammar) like Malaya (University of Pennsylvania) who analyze the NP coordination using LTAG and Kallmeyer (University Paris) who enrich TAG in semantic. This kind of analysis need to picturized the semantic meaning in tree structure. Although some research investigate the semantic meaning in particular word like the word understand in swedish by Allwood (Dept of Linguistics University of Göteborg). Only few of research analyze the derivational semantic meaning in full unit of conversation. 
This paper, somehow analyze the use of derivational words in students conversation scripts. Three phases (morphology, syntac, and semantic) analysis use to gain the data related to the use of derivational words by students

\section{METHOD}

The qualitative interpretative reasearch is use to analyze the processes of derivation in more detail by noting that a step in a derivation is usually actually not one process, but three simultaneous processes, namely: a morphological process (e.g. changing the shape of an existing word by adding a prefix or suffix morpheme to an existing root morpheme) a syntactic process (changing the part of speech of a word, e.g. from verb to noun) and a semantic process (producing a new sense). Because of the limited time, the writer only analyze the derivation types namely "addtion". While the conversation scripts that the writer use to analyze are 5 out of 22 scripts.

\section{FINDINGS and INTERPRETATIONS}

From the students' conversation script that have been analyze, the writer found out that many students use suffixes 'ed', 'ing', 's', like 'graduated', 'things', getting, etc, which is in morphological process belong to inflection because it didn't change the meaning of a words rather than change the tenses of a sentence. Many students didn't really aware with the use of derivational words. 3 numbers of students conversational scripts didn't insert any derivational words at all. While the other 2 insert very little derivational words they are:

1. Prayer

2. Brighten

3. Frendship

The other scripts use to explain 'make it bright' rather than 'brighten' and 'friends relationship' rather than ''friendship'. It shows that the students understanding in using derivational words to create more simple and systematic sentence are less.

After founding the derivational words that the students use in their conversation scripts, the following are the semantic analysis using the derivational words finding adapted from hurford (1983);

\begin{tabular}{|l|l|l|l|}
\hline $\begin{array}{l}\text { Derivational } \\
\text { words }\end{array}$ & $\begin{array}{l}\text { Morphological } \\
\text { process }\end{array}$ & Syntactic process & Semantic process \\
\hline Prayer & Add suffix -er & $\begin{array}{l}\text { Change verb to } \\
\text { noun or adjective }\end{array}$ & $\begin{array}{l}\text { Produce word } \\
\text { denoting an agent } \\
\text { or property }\end{array}$ \\
\hline Brighten & Add suffix -en & $\begin{array}{l}\text { Change adjective } \\
\text { to verb }\end{array}$ & $\begin{array}{l}\text { Produce word } \\
\text { denoting an act }\end{array}$ \\
\hline Friendship & $\begin{array}{l}\text { Compound word } \\
\text { friend - ship }\end{array}$ & $\begin{array}{l}\text { Compound noun } \\
\text { and noun }\end{array}$ & $\begin{array}{l}\text { Produce word } \\
\text { denoting an agent }\end{array}$ \\
\hline
\end{tabular}


Prayer in " $\mathrm{i}$ hope my prayer will be hear by him" shows that 'prayer' here not as an agent as someone who pray but as the property of the sentence.

Brighten in "so that it will brighten my skin" shows that 'brighten' here not as a property anymore rather than as an act to make my skin bright.

While friendship in "our friendship will be last forever'" it's the compunding of word friend and ship.

Based on the data above, we can conclude that derivation words have a big contribution to make the meaning in sentences meaningful without any long interpretation.

\section{CONCLUSION}

Based on the research finding above, the writer concluded that the students ability in using derivational words in their conversation is very low average. The students still use to explain certain words in long sentence than use its derivational word like prayer or brighten. It means that the students understanding in meaning or semantic meaning also still low. The students need more understanding about semantic derivation. Before that the students also need to be enriched their vocabulary to support their understanding in using derivational words. Because of the low level average of students semantic derivationl understanding, the teacher in this case especialy lecturer should be creative to enrich not only students vocabulary but also students understanding in derivation to use it in conversation, either daily conversation or classroom conversation.

\section{REFERENCES}

Hurford, R, James. 1983. Semantics a coursebook. Cambridge

Kreidler, W, Charles. 1998. Introducing English Semantics. Routledge

Griffiths, Patrick. 2006. An Introduction to English Semantics and Pragmatics. Edinburg University Press

Wardhaugh, Ronald. Introduction to Linguistics. McGraw-Hill Book Company.

O’ grady, William. 1996. Contemporary Linguistics, An introduction. Longman

Thornburry, Scott. How to Teach Speaking. Longman

Inch, S, Edward. 2006. Critical thinking and communication, the use of reason in argument. Pearson.

Walford, Geoffrey. 2001. Doing qualitative educational research, a personal guide to the research process. Continuum 
Babko-Malaya, Olga. LTAG semantics of NP coordination. Journal. University of Pennsylvania.

Kallmeyer, Laura. Enriching the TAG derivation tree for semantics. Journal. University Paris

Allwood, Jens. An Analysis semantic of Understanding. Journal. Dept of Linguistics University of Göteborg

Mirriam Webster Dictionary web 